\title{
Power Plateau and Anti-Power Phenomenon of Dual Active Bridge Converter with Phase-Shift Modulation
}

Xiao, Yudi; Zhang, Zhe; Xingkui, Mao; Tomas Manez, Kevin; Andersen, Michael A. E.

Published in:

Proceedings of 2018 IEEE Applied Power Electronics Conference and Exposition

Link to article, DOI:

10.1109/APEC.2018.8341272

Publication date:

2018

Document Version

Peer reviewed version

Link back to DTU Orbit

Citation (APA):

Xiao, Y., Zhang, Z., Xingkui, M., Tomas Manez, K., \& Andersen, M. A. E. (2018). Power Plateau and Anti-Power Phenomenon of Dual Active Bridge Converter with Phase-Shift Modulation. In Proceedings of 2018 IEEE Applied Power Electronics Conference and Exposition (pp. 1871-1875). IEEE. https://doi.org/10.1109/APEC.2018.8341272

\section{General rights}

Copyright and moral rights for the publications made accessible in the public portal are retained by the authors and/or other copyright owners and it is a condition of accessing publications that users recognise and abide by the legal requirements associated with these rights.

- Users may download and print one copy of any publication from the public portal for the purpose of private study or research.

- You may not further distribute the material or use it for any profit-making activity or commercial gain

- You may freely distribute the URL identifying the publication in the public portal 


\title{
Power Plateau and Anti-Power Phenomenon of Dual Active Bridge Converter with Phase-Shift Modulation
}

\author{
Yudi Xiao ${ }^{1,2}$, Zhe Zhang ${ }^{2}{ }^{*}$ Xingkui Mao ${ }^{1}$, Kevin Tomas Manez ${ }^{2}$, Michael A. E. Andersen ${ }^{2}$ \\ ${ }^{1}$ Dept. Electrical Engineering and Automation, Fuzhou University, Fuzhou City, China \\ ${ }^{2}$ Dept. Electrical Engineering, Technical University of Denmark, Kgs. Lyngby, Denmark \\ "mxk782@163.com
}

\begin{abstract}
In this paper, an improved power flow model for dual active bridge (DAB) converters with phase-shift modulation is introduced. Based on the analysis and the accordingly derived equations, a power plateau phenomenon, in which the phase shift loses its power-regulating capability, is investigated. Moreover, it is found that this power plateau phenomenon leads to an inversed power flow characteristic in some specific regions compared to the models reported in previous literature. The characteristics of the power plateau and its occurring conditions are derived and analyzed in depth. The calculations, simulations and analyses have been verified by experiments.
\end{abstract}

Keywords-dual active bridge; phase shift modulation; power flow model; power flow characteristics

\section{INTRODUCTION}

The utility grid, once passive and static with a limited number of distributed generators, is now more active and dynamic because of integration of distribution energy resources [1]-[2]. Therefore, solutions such as energy storage systems are required to improve grid reliability and stability [3]. Bidirectional dc-dc converters, which can interface energy storage systems to power conversion systems, have gained increasing attention [4]-[7]. Due to its small number of components, symmetrical structure, isolation capability and soft switching properties, the Dual Active Bridge (DAB) converter has become a popular topology for bidirectional dcdc power conversion [7].

Several analyses have been implemented on the power flow of DAB converters with a Single Phase-Shift Modulation (SPSM) [8]-[12]. In [8], the power flow equation for a singlephase DAB was derived without considering any losses nor dead time between switches in the same leg. In [9], the shorttime-scale transient processes in DAB converters with SPSM were discussed. However, no improvements in the power flow equation were made. In [10], an improved power flow equation was derived considering the dead-time effect and power semiconductor voltage drops, but the equation is not suitable for DAB converters using power MOSFETs; moreover the analyzed cases are limited. In [11], the power flow equation was derived considering MOSFET's ON resistance, and parasitic resistances of the inductor, transformer and $\mathrm{PCB}$ traces; however, the dead time effect was somehow neglected. In [12], the power flow equation was derived considering dead times. With those equations, some power flow characteristics

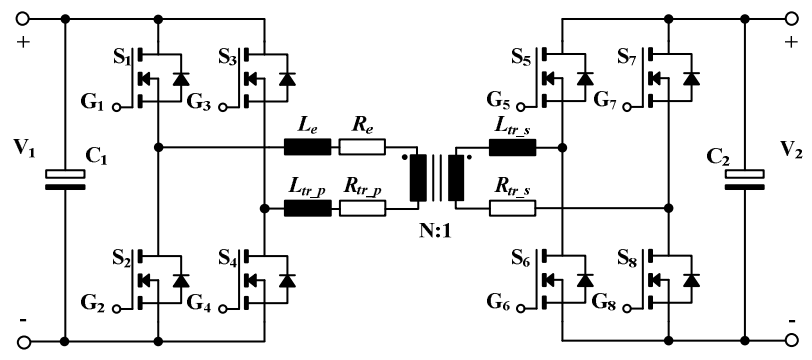

Fig. 1. Topology of a single-phase DAB converter.

were given, including the power plateau phenomenon which will be further investigated in this paper. However, the model in [12] does not consider any losses.

In this paper, an improved power flow model was derived considering both parasitic resistances and dead time effects. Based on the obtained equations, a power plateau phenomenon is investigated in depth. It is found that Due to the power plateau, the power flow characteristic of the $\mathrm{DAB}$ is inversed compared to the previous studies at some specific operation points. Therefore, a comprehensive modeling, as well as its corresponding analysis, is essential for design and control of DAB converters. All calculations and analyses match the simulations well. Furthermore, experimental results from a laboratory prototype verify the analysis, characteristics and influences of the power plateau.

\section{IMPROVED DAB MODELING AND ANALYSIS}

Fig. 1 shows a single-phase $\mathrm{DAB}$ converter, where the magnetizing inductance is neglected. $L_{e}$ and $R_{e}$ represent the inductance and winding resistance of the external inductor; $L_{t r}, R_{\text {tr } p}$ and $L_{t r_{-} s}, R_{t r_{-} s}$ represent the leakage inductance and the winding resistance of the transformer primary and secondary, respectively; MOSFETs are treated as a constant resistance when they are triggered ON by driving signals, and as a constant voltage drop when conducting reversely without driving signals; $\mathrm{G}_{1} \sim \mathrm{G}_{8}$ represent the driving signals; $V_{1}$ and $V_{2}$ are DC voltage sources; $V_{d H}$ and $R_{o n H}$ are the forward voltage of body-diodes and the ON resistance of MOSFETs in the bridge connected to $V_{1} ; V_{d L}$ and $R_{o n L}$ are those of MOSFETs in the bridge connected to $V_{2} ; T_{d}$ is the dead time; $f_{s}$ is the switching frequency. Input power $P_{i n}$ is defined as power sourcing from $V_{1}$, and output power $P_{o}$ is power sinking into $V_{2}$. 


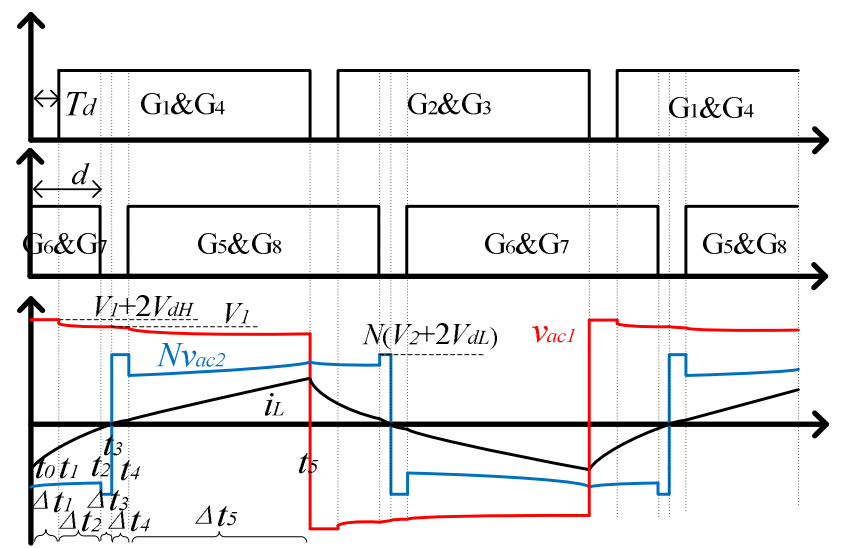

Fig. 2. Typical waveforms of the analyzed case.

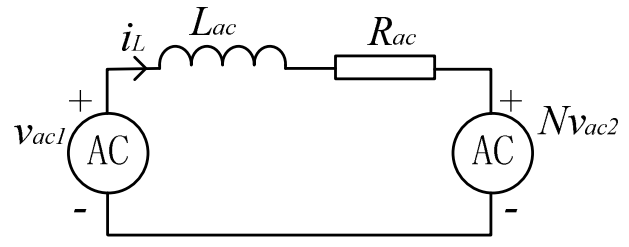

Fig. 3. Equivalent circuit of the DAB converter.

Here a special operation condition which leads to the power plateau phenomenon is analyzed. The typical waveforms of the $\mathrm{DAB}$ converter working in this case are given in Fig. 2, where assume $V_{1}>N V_{2}$ and commutation processes are neglected. The inductor current changes direction during the dead time of the active bridge connected to $V_{2}$. The unified phase shift $d$ is defined as:

$$
d=\frac{\beta}{\pi}
$$

where $\beta$ is the phase shift angle.

The equivalent circuit of the DAB converter illustrated in Fig. 1. can be derived as shown in Fig. 3 .

$L_{a c}$ and $R_{a c}$ are expressed:

$$
\begin{aligned}
& L_{a c}=L_{t r_{-} p}+N^{2} L_{t r_{-} s}+L_{e} \\
& R_{a c}=R_{t r_{-} p}+N^{2} R_{t r_{-} s}+R_{e}
\end{aligned}
$$

Based on Fig. 2, $v_{a c 1}, N v_{a c 2}$ and $i_{L}$ can then be expressed as follows.

$$
V_{a c 1}(t)=\left\{\begin{array}{l}
V_{1}+2 V_{d H}, t \in\left[t_{0}, t_{1}\right] \\
V_{1}-2 R_{o n H} \cdot i_{L}(t), t \in\left(t_{1}, t_{2}\right] \\
V_{1}-2 R_{o n H} \cdot i_{L}(t), t \in\left(t_{2}, t_{3}\right] \\
V_{1}-2 R_{o n H} \cdot i_{L}(t), t \in\left(t_{3}, t_{4}\right] \\
V_{1}-2 R_{o n H} \cdot i_{L}(t), t \in\left[t_{4}, t_{5}\right]
\end{array}\right.
$$

$$
\begin{gathered}
N v_{a c 2}=\left\{\begin{array}{l}
-N\left(V_{2}-2 R_{o n L} N \cdot i_{L}(t)\right), t \in\left[t_{0}, t_{1}\right] \\
-N\left(V_{2}-2 R_{o n L} N \cdot i_{L}(t)\right), t \in\left(t_{1}, t_{2}\right] \\
-N\left(V_{2}+2 V_{d L}\right), t \in\left(t_{2}, t_{3}\right] \\
N\left(V_{2}+2 V_{d L}\right), t \in\left(t_{3}, t_{4}\right] \\
N\left(V_{2}+2 R_{o n L} N \cdot i_{L}(t)\right), t \in\left[t_{4}, t_{5}\right]
\end{array}\right. \\
i_{L}(t)=\left\{\begin{array}{l}
i_{L}\left(t_{0}\right) \cdot e^{-J_{1}\left(t-t_{0}\right)}+M_{1}\left[1-e^{-J_{1}\left(t-t_{0}\right)}\right], t \in\left[t_{0}, t_{1}\right] \\
i_{L}\left(t_{1}\right) \cdot e^{-J_{2}\left(t-t_{1}\right)}+M_{2}\left[1-e^{-J_{2}\left(t-t_{1}\right)}\right], t \in\left(t_{1}, t_{2}\right] \\
i_{L}\left(t_{2}\right) \cdot e^{-J_{3}\left(t-t_{3}\right)}+M_{3}\left[1-e^{-J_{3}\left(t-t_{2}\right)}\right], t \in\left(t_{2}, t_{3}\right] \\
i_{L}\left(t_{3}\right) \cdot e^{-J_{4}\left(t-t_{3}\right)}+M_{4}\left[1-e^{-J_{4}\left(t-t_{3}\right)}\right], t \in\left(t_{3}, t_{4}\right] \\
i_{L}\left(t_{4}\right) \cdot e^{-J_{5}\left(t-t_{4}\right)}+M_{5}\left[1-e^{-J_{5}\left(t-t_{4}\right)}\right], t \in\left[t_{4}, t_{5}\right]
\end{array}\right.
\end{gathered}
$$

where $J_{I} \sim J_{5}$ and $M_{1} \sim M_{5}$ are given in Table. 1.

Moreover, from Fig. 2, the following equations can be obtained.

At the end of half cycle:

$$
\left\{\begin{array}{l}
\Delta t_{1}=T_{d} \\
\Delta t_{2}=\frac{d}{2 f_{s}}-T_{d} \\
t_{4}-t_{2}=T_{d} \\
i_{L}\left(t_{3}\right)=0 \\
t_{5}-t_{0}=\frac{1}{2 f_{s}}
\end{array}\right.
$$

$$
i_{L}\left(t_{5}\right)=-i_{L}\left(t_{0}\right)
$$

Based on (8), the following equation can be obtained:

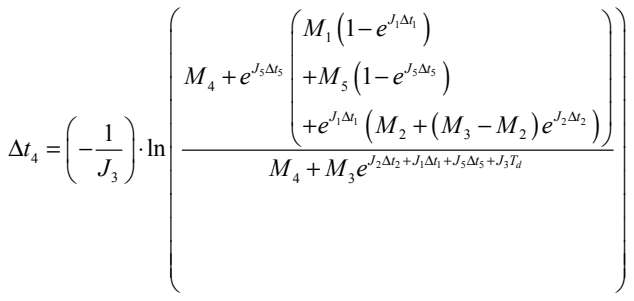

TABLE 1 EXPRESSIONS FOR $J_{l} \sim J_{5}$ AND $M_{l} \sim M_{5}$

\begin{tabular}{|c|c|c|c|}
\hline $\boldsymbol{J}_{1}$ & $\frac{R_{a c}+2 N^{2} R_{o n L}}{L_{a c}}$ & $\boldsymbol{M}_{1}$ & $\frac{V_{1}+2 V_{d H}+N V_{2}}{R_{a c}+2 N^{2} R_{o n L}}$ \\
\hline $\boldsymbol{J}_{2}$ & $\frac{R_{a c}+2 R_{o n H}+2 N^{2} R_{o n L}}{L_{a c}}$ & $\boldsymbol{M}_{2}$ & $\frac{V_{1}+N V_{2}}{R_{a c}+2 R_{o n H}+2 N^{2} R_{o n L}}$ \\
\hline $\boldsymbol{J}_{3}$ & $\frac{R_{a c}+2 R_{o n H}}{L_{a c}}$ & $\boldsymbol{M}_{3}$ & $\frac{V_{1}+N\left(V_{2}+2 V_{d L}\right)}{R_{a c}+2 R_{o n H}}$ \\
\hline $\boldsymbol{J}_{4}$ & $\frac{R_{a c}+2 R_{o n H}}{L_{a c}}$ & $\boldsymbol{M}_{4}$ & $\frac{V_{1}-N\left(V_{2}+2 V_{d L}\right)}{R_{a c}+2 R_{o n H}}$ \\
\hline $\boldsymbol{J}_{5}$ & $\frac{R_{a c}+2 R_{o n H}+2 N^{2} R_{o n L}}{L_{a c}}$ & $\boldsymbol{M}_{5}$ & $\frac{V_{1}-N V_{2}}{R_{a c}+2 R_{o n H}+2 N^{2} R_{o n L}}$ \\
\hline
\end{tabular}




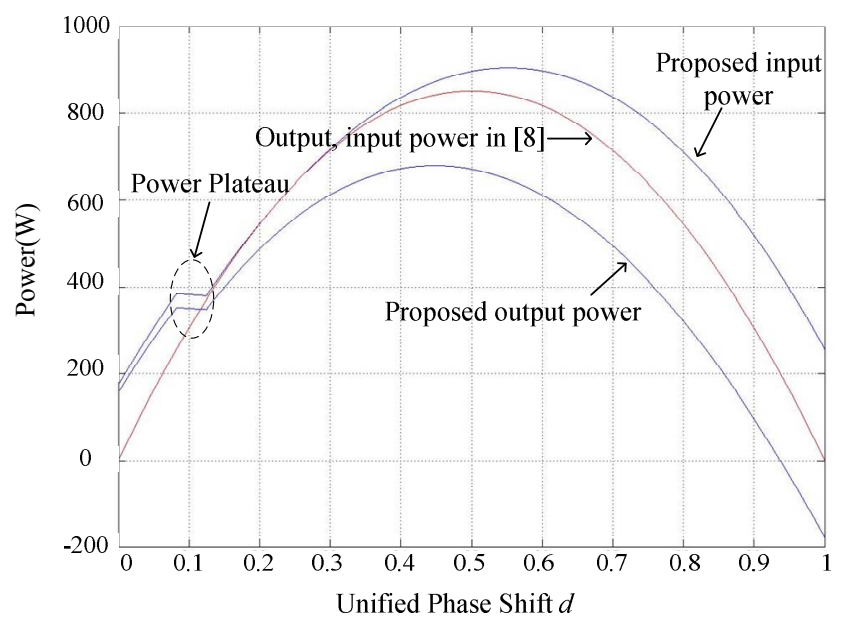

Fig.4. Calculated power flow characteristics.

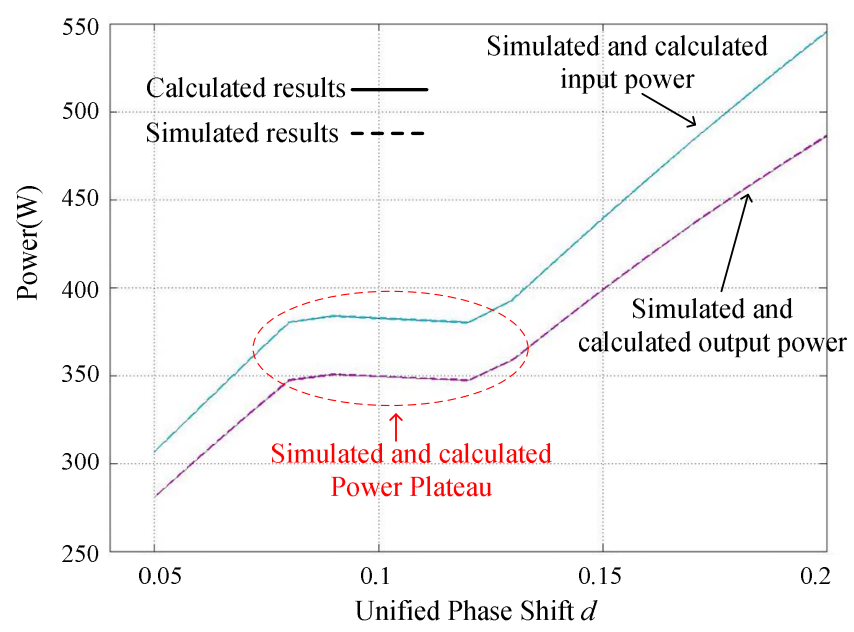

Fig. 5. Calculated and simulated power flow characteristics.

With (9), (7) and (4) (6), $P_{\text {in }}$ and $P_{o}$ can be calculated as:

$$
\begin{gathered}
P_{i n}=2 V_{1} f_{s}\left(I n t_{1}+I n t_{2}+I n t_{3}+I n t_{4}+I n t_{5}\right) \\
P_{o}=2 V_{2} \cdot N f_{s}\left(-I n t_{1}-I_{2} t_{2}-I_{3} t_{3}+I_{4} t_{4}+I_{5}\right)
\end{gathered}
$$

where $I n t_{i}(1 \leq \mathrm{i} \leq 5)$ are the averaged $i_{L}$ during interval $\Delta t_{i}$, whose expressions are given as follows:

$$
\left\{\begin{array}{l}
\text { Int }_{1}=M_{1} \Delta t_{1}+\left[i_{L}\left(t_{0}\right)-M_{1}\right]\left(-\frac{1}{J_{1}}\right)\left(e^{-J_{1} \Delta t_{1}}-1\right) \\
\text { Int }_{2}=M_{2} \Delta t_{2}+\left[i_{L}\left(t_{1}\right)-M_{2}\right]\left(-\frac{1}{J_{2}}\right)\left(e^{-J_{2} \Delta t_{2}}-1\right) \\
\text { Int }_{3}=M_{3} \Delta t_{3}+\left[i_{L}\left(t_{2}\right)-M_{3}\right]\left(-\frac{1}{J_{3}}\right)\left(e^{-J_{3} \Delta t_{3}}-1\right) \\
\text { Int }_{4}=M_{4} \Delta t_{4}+\left[i_{L}\left(t_{3}\right)-M_{4}\right]\left(-\frac{1}{J_{4}}\right)\left(e^{-J_{4} \Delta t_{4}}-1\right) \\
\text { Int }_{5}=M_{5} \Delta t_{5}+\left[i_{L}\left(t_{4}\right)-M_{5}\right]\left(-\frac{1}{J_{5}}\right)\left(e^{-J_{5} \Delta t_{5}}-1\right)
\end{array}\right.
$$

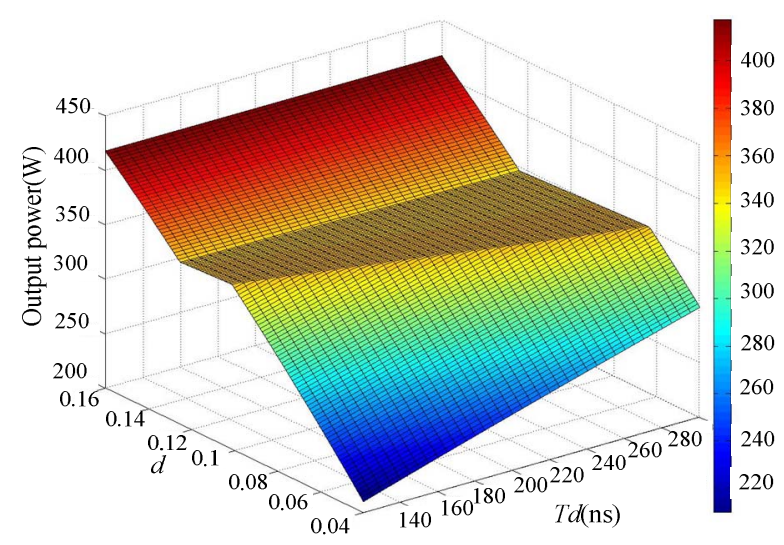

Fig. 6. Calculated output power as a function of $d \& T_{d}$

Therefore, the calculated power flow here in (10) and (11) for $\mathrm{V}_{1}>N \mathrm{~V}_{2}$, and those proposed in [8] are plotted in Fig. 4 (the adopted parameters are given in Table 2). As shown, when $d$ is

\begin{tabular}{|c|c|c|c|c|}
\hline$V_{1}$ & $V_{2}$ & $f_{\mathrm{s}}$ & $T_{d}$ & $V_{d H}$ \\
\hline $200 \mathrm{~V}$ & $30 \mathrm{~V}$ & $100 \mathrm{kHz}$ & $210 \mathrm{~ns}$ & $4.8 \mathrm{~V}$ \\
\hline$V_{d L}$ & $\boldsymbol{R}_{\text {onH }}$ & $\boldsymbol{R}_{\text {onL }}$ & $\boldsymbol{R}_{e}$ & $L_{e}$ \\
\hline $0.9 \mathrm{~V}$ & $65 \mathrm{~m} \Omega$ & $1.9 \mathrm{~m} \Omega$ & $52 \mathrm{~m} \Omega$ & $41.2 \mathrm{uH}$ \\
\hline$N$ & $\boldsymbol{R}_{\text {tr } p}$ & $\boldsymbol{R}_{t r} s$ & $L_{t r p}$ & $L_{t r s} s$ \\
\hline $14 / 3$ & $1.8 \Omega$ & $80 \mathrm{~m} \Omega$ & $2.5 \mathrm{uH}$ & $112 \mathrm{nH}$ \\
\hline
\end{tabular}
$0.08 \sim 0.13$, the input and output power do not keep increasing, and even decreases, which is against the results in [8]-[11]. The so-called power plateau phenomenon appears. The simulated and calculated input and output power are presented in Fig. 5 and they match very well, thus the proposed calculations are verified.

\section{Characteristics OF POWER Plateau}

Given $\mathrm{V}_{1}>N \mathrm{~V}_{2}$, the calculations are done to investigate which parameters may have impact on the plateau's length i.e. phase shift range and where the plateau occurs. The conclusion is that $T_{d}$ affects the power plateau's length and location, depending on certain $N, L_{e}, V_{d H}, V_{d L}, R_{o n H}$, and $R_{o n L}$ since $N, L_{e}$ are mainly determined by the required power, and $V_{d H}, V_{d L}$, $R_{o n H}, R_{\text {onL }}$ are constant once MOSFETs are selected. The influences of $V_{2}$ are given in section IV. As shown in Fig. 6, with the dead time increasing, the length of the power plateau increases, and its starting points shift to a smaller phase shift angle; however, the ending points keep unchanged.

\section{EFFeCts of Power Plateau on DAB OPERATion}

During the power plateau, the power flow is unable to be regulated over certain phase shift ranges. Especially in high power applications, where the phase shift angle is usually limited to small values (below $\pi / 4$ ) to suppress reactive power loss, the power plateau takes a large portion of the allowable phase shift angle range and thereby has a negative impact on the converter control.

Moreover, during the plateau, the DAB's power no longer increases (or decreases) with increasing (or decreasing) lagging 


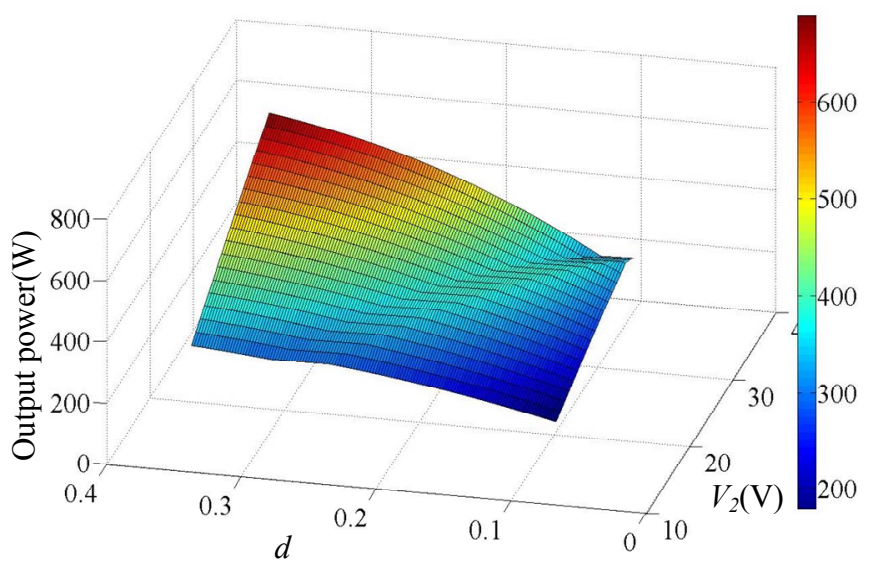

Fig. 7. Calculated output power as a function of $d$ and $V_{2}$.

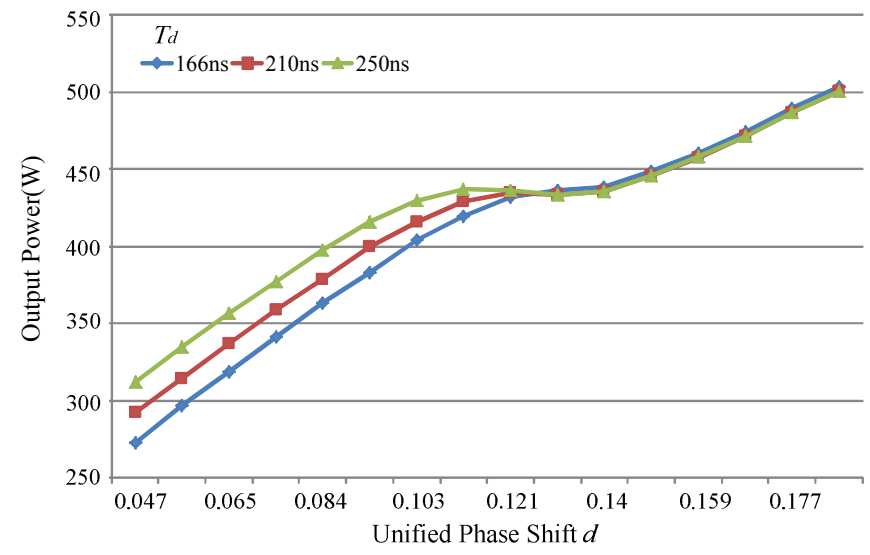

Fig. 9. Measured output power as a function of $d \& T_{d}$

bridge DC voltage $V_{2}$, and it is named as anti-power phenomenon. Using the parameters listed in Table 2, the calculated output power as a function of $d$ and $V_{2}$ is plotted in Fig. 7. As shown, at a specific phase shift angle, the output power will increase (or decrease) with decreasing (or increasing) $V_{2}$ over the specific $V_{2}$ range.

\section{EXPERIMENTAL RESULTS}

In order to verify the theoretical analysis, a laboratory prototype with the same parameters given in Table 2 is constructed and tested. Fig. 9 plots the output power as a function of $d$ at different $T_{d}$. A power plateau can be seen clearly at different $T_{d}$, therefore, the existence of power plateau and its associated analysis in section III are verified. Fig. 10 and Fig. 11 show the measured waveforms of the transformer port voltages, inductor current and driving signals of the MOSFETs in the $V_{2}$ active bridge with $d=0.14$ and $T_{d}=210 \mathrm{~ns}$. As shown, the inductor current changes its direction during the dead time so that this can verify the analysis given in Fig. 2 . Fig. 12 shows that the power flow characteristic is inversed at the specific $V_{2}$ values. Due to the anti-power phenomenon, additional concerns must be taken in DAB power regulation, especially when on-line calculations [13]-[15] are used.

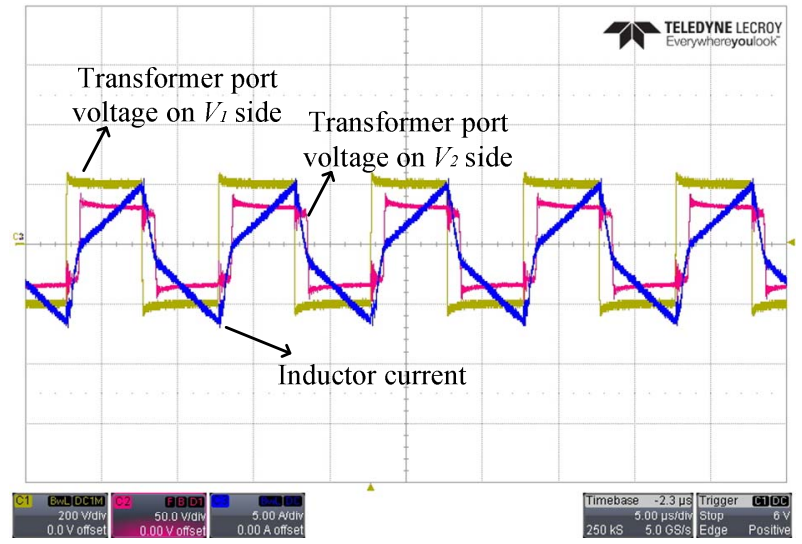

Fig. 10. Measured transformer voltages and inductor current at $d=0.14 \&$ $T_{d}=210 \mathrm{~ns}$

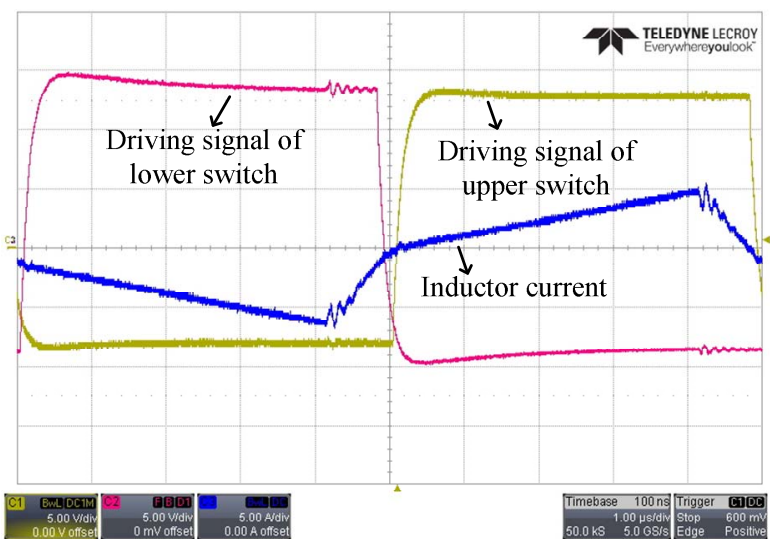

Fig. 11. Measured driving signals for MOSFETs in lagging bridge at $d=0.14$ and $T_{d}=210 \mathrm{~ns}$.

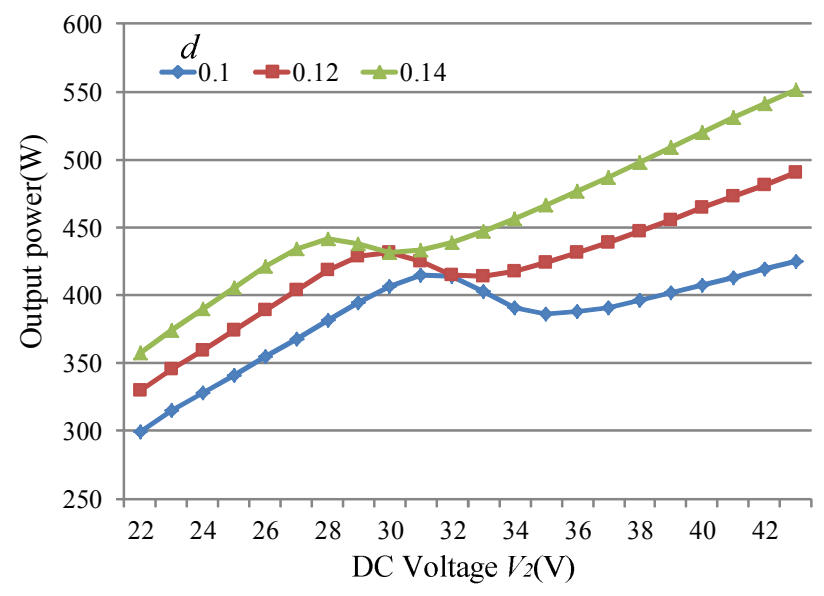

Fig. 12. Measured output power as a function of $d \& V_{2}$

\section{CONCLUSIONS}

In this paper, an improved power flow model for the singlephase DAB converter with phase shift control is derived, considering the conduction loss of MOSFETs and magnetic components and the dead time effects. A special operating condition in which inductor current changes direction during the dead time leads to the so-called power plateau in which the phase shift becomes unable to regulate the power flow. The 
power plateau leads to different power flow characteristics compared to the results reported in previous investigations. Thereby, the characteristics of the power plateau are studied, and the impact due to dead time on the power plateau is addressed. All the theoretical analysis, calculations and simulations are verified by experiments. For the cases of $\mathrm{V}_{1}<N \mathrm{~V}_{2}$ and for DAB converters with modulation schemes other than a single phase shift modulation, more investigations to study the DAB converter's power flow characteristics are needed in the future.

\section{REFERENCES}

[1] Q. C. Zhong, "Power electronics-enabled autonomous power systems: architecture and technical routes", IEEE Transactions on Industrial Electronics, vol. 64, no. 7, pp. 5907-5918, Jul. 2017.

[2] L. F. Costa, G. D. Carne, G. Butic chi, M. Liserre, "The smart transformer: a solid-state transformer tailored to provide ancillary services to the distribution grid", IEEE Power Electronics Magazine, vol. 4, no. 2, pp. 56-67, Jun. 2017.

[3] Y. Xu, C. Singh, "Power system reliability impact of energy storage integration with intelligent operation strategy", IEEE Transactions on Smart Grid, vol. 5, no. 2, pp. 1129-1137, Aug. 2013.

[4] K. Kruse, M. Elbo, Z. Zhang, "GaN-based high efficiency bidirectional DC-DC converter with $10 \mathrm{MHz}$ switching frequency", IEEE Applied Power Electronics Conference and Exposition (APEC), pp. 273-278, Mar. 2017.

[5] B. Li, F. C. Lee, Q. Li, Z. Y. Liu, "Bi-directional on-board charger architecture and control for achieving ultra-high efficiency with wide battery voltage range", IEEE Applied Power Electronics Conference and Exposition (APEC), pp. 3688-3694, Mar. 2017.

[6] R. M. Burkart, J. W. Kolar, "Comparative $\eta-\rho-\sigma$ Pareto optimization of Si and $\mathrm{SiC}$ multilevel Dual-Active-Bridge topologies with wide input voltage range", IEEE Transactions on Power Electronics, vol. 32, no. 7, pp. 5258-5270, Jul. 2017.

[7] F. Xue, R. Y. Yu, A. Q. Huang, "A 98.3\% efficient GaN isolated bidirectional DC-DC converter for DC Microgrid energy storage system applications", IEEE Transactions on Industrial Electronics, no. 99, Mar. 2017.

[8] R. W. A. A. De. Doncker, D. M. Divan, M. H. Kheraluwala, "A threephase soft-switched high-power-density DC/DC converter for highpower applications", IEEE Transactions on Industrial Applications, vol. 27,no. 1, pp. 63-73, Jan/Feb. 1991.

[9] H. Bai, C. C. Mi, S. Gargies, "The short-time-scale transient processes in high-voltage and high-power isolated bidirectional DC-DC converters", IEEE Transactions on Power Electronics, vol. 23, no. 6, pp. 2648-2656, Nov. 2008

[10] Y. H. Xie, J. Sun, J. S. Freudenberg, "Power flow characterization of a bidirectional galvanically isolated high-power DC/DC converter over a wide operating range", IEEE Transactions on Power Electronics, vol. 25, no. 1, pp. 54-66, Jan. 2010.

[11] F. Krismer, "Modeling and optimization of bidirectional dual active bridge DC-DC converter", Dissertation submitted to ETH Zurich for the Degree of Doctor of Sciences, 2010.

[12] B. Zhao, Q. Song, W. H. Liu, Y. D. Sun, "Dead time effect of the high frequency isolated bidirectional full bridge $\mathrm{dc}-\mathrm{dc}$ converter: comprehensive theoretical analysis and experimental verification", IEEE Transactions on Power Electronics, vol. 29, No. 4, 2014: 1667-1680.

[13] H. Bai, Z. L. Nie, C. C. Mi, "A model-based dead-band compensation for the Dual-Active-Bridge isolated bidirectional DC-DC converter", IEEJ Transactions on Electrical and Electronic Engineering, pp. 517-524, Sep. 2011.

[14] D. Costinett, D. Maksimovic, R. Zane, "Design and control for high efficiency in high step-down dual active bridge converters operating at high switching frequency", IEEE Transactions on Power Electronics, vol. 28, no. 8, pp. 3931-3940, Aug. 2013.

[15] R. Zgheib, K. Al-Haddad, "Neural network controller to manage the power flow of a hybrid source for electric vehicles", IEEE Vehicle Power and Propulsion Conference(VPPC), Oct. 2015. 